\title{
Educational Aspects of Interactions With the Pharmaceutical Industry
}

\author{
Richard Balon, M.D.
}

$\mathrm{M}$ edicine's relationship with the pharmaceutical industry, like other relationships, has gone through many peripeteias, from being too cozy in the past to being controversial at best in the present. This relationship is definitely very complicated. It stirs up passionate responses in many and longing for the "good old times" in some. Numerous articles have been published over the years addressing this relationship. This issue of Academic Psychiatry brings two more: one study of resident and faculty views on the interaction with the pharmaceutical industry by Misra and colleagues (1) and a review of key aspects in interactions between academia and the pharmaceutical industry by Jain (2).

In Misra and colleagues' (1) survey of psychiatric residents and faculty at Oregon Health and Science Center, most respondents disagreed that pharmaceutical representatives had an important teaching role at the medical school. Residents and faculty also mistrusted the information that pharmaceutical representatives offer but believed that the loss of financial support from industry does adversely affect educational and other highly valued activities. One would say that these are interesting, yet not surprising, findings. Nevertheless, the fact that anyone in this study agreed that pharmaceutical representatives have an important teaching role is surprising, as is anyone even asking the question in this survey. Pharmaceutical representatives do not have any teaching role during medical school, residency, and continuing medical education. They provide information (which is really not teaching), medication samples, or maybe dinner talk invitations. Assuming that pharmaceutical representatives may have a teaching role seems to be one key problem in the complicated relationship between academic medicine and the pharma-

Received and accepted September 9, 2009. Dr. Balon is affiliated with University Psychiatric Center and Wayne State University in Detroit, MI. Address correspondence to Richard Balon, M.D., University Psychiatric Center, 2751 E Jefferson, Ste 200, Detroit, MI 48207; rbalon@wayne. edu (e-mail).

Copyright (C) 2010 Academic Psychiatry ceutical industry. The role of the pharmaceutical industry is to sell products using marketing and sales strategies, not to teach. If we do not acknowledge the true role and working methods of the pharmaceutical industry, we will be in trouble.

The review article by Jain (2) brings attention to another factor in this complicated relationship-we have not been formally teaching about the relationship between the medical profession and the pharmaceutical industry; we are only beginning to do so. Though Jain (2) mentions formal didactics on the subject and various institutional policies as a possible remedy, these two measures may not be good enough. A few hours of didactics (which is all programs could and would devote to this topic, if at all) do not capture everything within a particular area and do not provide experience. Didactics cannot address all life situations. Using the interaction with pharmaceutical representatives in teaching could be a very practical and experiential addition to education on the interaction with pharmaceutical industry. Maybe the total ban on interaction with pharmaceutical representatives introduced in many academic institutions is a bit counterproductive. As Dubovsky and Dubovsky (3) emphasize, this approach does not teach residents how to deal with the interaction constructively; residents will not know how to critically interpret the information they receive. Would not supervised interaction between residents and pharmaceutical representatives better prepare residents for the onslaught of pharmaceutical interactions once residents begin their practices? Are we not reneging on our true educational duty to prepare the next generation of physicians for informed and ethical dealing with the pharmaceutical industry? Maybe it is time to reevaluate our reaction and approach to interactions with the pharmaceutical industry and use this interaction within the educational framework. The experience of interaction could significantly enhance our educational mission.

I am not advocating the return to the old style of inter- 
actions or accepting any gifts or funding of various activities. Similar to what Dubovsky and Dubovsky (3) propose in their book on dealing with the industry, I am suggesting a controlled, faculty-supervised interaction between residents and pharmaceutical representatives, but without any monetary or other goods exchanged. The interactions may provide trainees and even faculty with an invaluable experience of subtlety and sophistication of marketing that is barely possible to capture in any lecture.

An example of the complexity and subtlety one has to be able to understand and untangle when presented information by a pharmaceutical representative is the following discussion about one of the newer antipsychotics. In a response to a question about whether this medication was abused by prisoners, the pharmaceutical representative replied that although it was true in the past, as prisoners tried to "sleep through their prison terms" (a subtle suggestion that this medication works for sleep), the newer, slowrelease form is not abused anymore (inconspicuously marketing the new, more expensive form here), and now prisoners are abusing other, very sedating antipsychotics (a subtle negative comment about competitors' products). Finally, the representative added two more interesting marketing comments: that the majority of patients abusing various substances have some symptoms of bipolar disorder (suggesting that a possible underlying disorder could be helped by the presented antipsychotic) and that according to the STAR*D study, only one-third of depressed patients are really helped by treatment with antidepressants and thus one should think about prescribing antipsychotics to this population, if not alone, at least in combination with antidepressants.

Only a concrete, specific case example like this can capture all the subtleties and provide a unique educational experience. Didactic teaching is always going to be a step or two behind life experience. Unless trainees are exposed to the marketing strategies in vivo, under supervision, and with explanations of these strategies and their background, they will not be able to discern them during their first pharmaceutical representative visit after they graduate. In addition, if interaction with industry is abolished from educational programs, supervisors will also lose experience, which will make future generations of physicians more vulnerable to pharmaceutical marketing strategies.

Disclosures of Academic Psychiatry editors are published in each January issue.

\section{References}

1. Misra S, Ganzini L, Keepers G: Psychiatric resident and faculty views on and interactions with the pharmaceutical industry. Acad Psychiatry 2010; 34:102-108

2. Jain S: Key aspects of physician and pharmaceutical industry relationships for trainees. Acad Psychiatry 2010; 34: 98-101

3. Dubovsky AN, Dubovsky SL: Psychotropic Drug Prescriber's Survival Guide: Ethical Mental Health Treatment in the Age of Big Pharma. New York, Norton, 2007 